\title{
Catalytic Oxidation of Olefins
}

\author{
Zhang Yongmei ${ }^{1}$ and You Hongjun ${ }^{*}, 2$ \\ ${ }^{1}$ Liaoning Shihua University, Fushun, Liaoning, P.R. China \\ ${ }^{2}$ SAIT Polytechnic, Calgary AB, Canada
}

\begin{abstract}
This paper introduces the development circumstance of catalytic oxidation of olefins. And the synthesis method of catalytic oxidation of olefins are discussed in detail, such as, catalytic gas-phase oxidation of olefins; catalytic liquidphase oxidation of olefins; catalytic oxidation of enzyme; catalytic oxidation of olefins by using sodium hypochlorite and hydrogen peroxide as the catalyst; directly catalytic oxidation of olefins by using visible light. When hydrogen peroxide is used as the catalyst, it has no pollution and is good beneficial to the public.
\end{abstract}

Keywords: Olefin, catalytic, oxidation, hydrogen peroxide, public.

\section{INTRODUCTION}

Olefin derivative (such as, epoxy compound, aldehyde and ketone) is one of an important chemical production. And it can be got by using the oxidation method or hydrolysis method. The developed countries use catalytic oxidation method instead of non-catalytic oxidation method in order to decrease pollutant and prevent an environment [1]. Oxygen is one of the common oxidant and is used in the given reaction, such as; oxygen reacts with ethylene to produce ethylene oxide. But the reaction conditions (such as, high temperature and high pressure) have an obvious effect on these reactions so their appliances are limited in practical. These homogeneous catalytic reactions (epoxy reaction, olefin oxidation and allyl oxidation) under the condition of the transition metal catalyst occur at the room temperature or close to the room temperature [2].

In this paper, the three main methods, directly catalytic oxidation of olefins and catalytic oxidation of olefins by using sodium hypochlorite and hydrogen peroxide as the catalyst and directly catalytic oxidation of olefin by using visible light, are introduced.

\section{CATALYTIC OXIDATION OF OLEFINS}

\section{Directly Catalytic Oxidation of Olefins}

\section{Catalytic Gas-Phase Oxidation of Olefins}

Detlef Stockight [3] introduced that the catalytic potential of $\mathrm{Fe}(\mathrm{L})^{+}$complexes $(\mathrm{L}=$ benzene, pyridine, naphthalene) with respect to oxygen convert to alkenes in the gas phase had been investigated by using Fourier-transform ion cyclotron resonance mass spectrometry. Oxidation of $\mathrm{Fe}(\mathrm{L})^{+}$ with $\mathrm{N}_{2} \mathrm{O}$ leaded to $\mathrm{Fe}(\mathrm{L}) \mathrm{O}^{+}$with reaction efficiencies of $86 \%(\mathrm{~L}=$ benzene $), 40 \%(\mathrm{~L}=$ pyridine $)$, and $44 \%(\mathrm{~L}=$ naphthalene), respectively. While "naked" $\mathrm{FeO}^{+}$behaves as a powerful CC- and $\mathrm{CH}$-bond activation reagent, the ligated species $\mathrm{Fe}(\mathrm{L}) \mathrm{O}^{+}$were entirely unreactive in that condition.

*Address correspondence to this author at the Unit 86829 , Centre Street, NW Calgary, T2K5C4, Canada; Tel: (403) 275-7064;

E-mail: youhongjun@hotmail.com
However, oxygen convert from $\mathrm{Fe}(\mathrm{L}) \mathrm{O}^{+}$to olefins occurred at the collision rate with less than $10 \%$ formation of byproducts. Indirect evidence was presented suggesting that the $\mathrm{O}$-atom transfer from $\mathrm{Fe}(\mathrm{L}) \mathrm{O}^{+}$to olefins didn't produce ketones or aldehydes; rather, epoxide formation was brought about. The largest turnover number $\left(\mathrm{n}_{\mathrm{t}}\right)$ was obtained for the $\mathrm{Fe}\left(\mathrm{C}_{6} \mathrm{H}_{6}\right) \mathrm{O}^{+} / \mathrm{C}_{2} \mathrm{H}_{4}$ system with $\mathrm{n}_{\mathrm{t}}=6$.

R. J. Chimentao [4] explained that shape which was controlled metal nanoparticles was studied in the epoxidation of olefins. Polyvinylpyrrolidone (PVP) mediated polyol processes were used to produce silver nanowires/rods, nanocubes and nanopolyhedra. Spherical copper nanoparticles were also gotten by using the polyol process. The mean diameter of the silver nanoparticles was about $150 \mathrm{~nm}$. Furthermore, $\mathrm{Cu}$ nanoparticles were obtained in an ethanol solution by applying CTAB as surfactant and as reducing agent. Additionally Au nanoparticles were obtained by using a phase-transfer system irradiated with $254 \mathrm{~nm}$ UV light. The mean diameter of these $\mathrm{Au}$ and $\mathrm{Cu}$ nanoparticles was about $10 \mathrm{~nm}$. The catalytic activity of these nanoparticles on several supports such as $-\mathrm{Al}_{2} \mathrm{O}_{3}, \mathrm{CaCO}_{3}$ and spherical particles of $\mathrm{TiO}_{2}$ gotten by the $\mathrm{St}$ ber method was studied in the epoxidation of a no-allylic olefin such as styrene, as well as for an allylic olefin, such as propane, using molecular oxygen and $\mathrm{N}_{2} \mathrm{O}$ as oxidants. The effect of Cs promotion in the styrene epoxidation was also researched. The type of metal, the particle size, the support and the oxidant, as well as the addition of promoters such as Cs, indicated a strong influence on the formation of selective oxidation products.

\section{Catalytic Liquid-Phase Oxidation of Olefins}

Maria Ziolek [5] reviewed the discoveries and/or knowledge developed in the past 10 years in the area of catalytic liquid-phase oxidation with hydrogen peroxide on mesoporous molecular sieves of MCM-41 type modified with various transition metals. The following parameters influencing activity and selectivity of the catalysts were discussed: nature of matrix for metal species limiting diffusion effects; isolation of metals; hydrophobicity of catalysts; nature of solvent; reducibility of metal species; 
leaching of metal from the solid. Advantages and disadvantages of MCM-41 materials are pointed out in relation to the properties of TS- 1 and TS- 2 zeolites. There are as follows: no diffusion limitation especially if metal is lived in the centre of MCM-41; metal easily goes into the framework; isolation of metal easily arrives at than in zeolites; reducibility of metal species is easily ordered by changing pores sizes to determine Ti-O-Ti single.

\section{Catalytic Oxidation of Enzyme}

Roger Appelqvist [6] introduced a chemically modified electrode for detection of dihydronicotinamide adenine dinucleotide (NADH) and dihydronicotinamide adenine dinucleotide phosphate (NADPH). Graphite rods were modified by dipping them into solutions of-dimethylamino1, 2-benzophenoxzinium salt (Meldola blue). The modified electrodes were mounted in a flow-through cell in a flowinjection manifold. Samples $(50 \mu \mathrm{l})$ of pure nicotinamide coenzymes produced strictly linear calibration graphs from 1 $\mu \mathrm{M}$ to $10 \mathrm{mM}$ with a repeatability of $0.2-0.6 \%$ RSD. A packed-bed enzyme reactor $(210 \mu \mathrm{l})$ containing immobilized glucose dehydrogenase was inserted in the manifold for glucose determinations. Oxidized coenzyme was also added to the carrier electrolyte. Straight calibration graphs were again obtained up to $1 \mathrm{mM} \beta$-D-glucose. The detection limit was $0.25 \mu \mathrm{M} \beta$-D-glucose for $50-\mu 1$ samples. The electrode was kept at -50 to $0 \mathrm{~m} \mathrm{~V}$ vs.

Catalytic Oxidation of Olefins by Using Sodium Hypochlorite and Hydrogen Peroxide as the Catalyst

Catalytic Oxidation of Olefins by Using Sodium Hypochlorite as the Catalyst

Debabrata Chatterjee [7] introduced that new Schiff-base complexes of Nickel (II), $\mathrm{NiL}^{1}$ (where $\mathrm{H}_{2} \mathrm{~L}^{1}=\mathrm{N}, \mathrm{N}^{\prime}$-bis(2hydroxyphenyl)ethylenediimine) and $\mathrm{NiL}^{2}$ (where $\mathrm{H}_{2} \mathrm{~L}^{2}=\mathrm{N}$ ((2-hydroxyphenyl)acetylaldimine)-N'-(2-hydroxyphenyl)acetamide) had been prepared in good yield by direct interaction of 2-aminophenol, glyoxal/methylacetatotate and $\mathrm{NiCl}_{2}$ and characterised by physico-chemical analysis. Catalytic ability of NiL complex were examined and found that both the complexes can effectively catalyze the epoxidation of olefins viz. cyclohexene, 1-hexene, cis- and trans-stilbenes, indene with $\mathrm{NaOCl}$.

\section{Catalytic Oxidation of Olefins by Using Hydrogen Peroxide as the Catalyst}

Zhang Zhenxin [8] explained that inorganic-organic hybrid material was formed by $\left[\mathrm{PW}_{11} \mathrm{O}_{39}\right]^{7-}$ and benzene- 1,3,5-[tris(phenyl-4-carboxylic acid)] tris (2-trimethylammonium ethyl) ester. This hybrid material behaved as a very effective and selective heterogeneous catalyst for the epoxidation of olefins with hydrogen peroxide as an oxidant. This heterogeneous catalyst could be easily recovered and reused after reaction without loss of activity.

A heterogeneous catalytic material for epoxidation has been synthesized by preparing insoluble inorganic-organic hybrid compounds based on a tripodal organic triammonium cation and a catalytically active POM $\left[\mathrm{PW}_{11} \mathrm{O}_{39}\right]^{7-}$. The molecular formula of POM $\left[\mathrm{PW}_{11} \mathrm{O}_{39}\right]^{7-}$ are listed as follows:

\section{Directly Catalytic Oxidation of Olefins by Using Light}

\section{Visible Light Reaction of Olefins Under the Condition of Metallic Complexes of Porphyrins}

Debabrata Chatterjee [9] explained that mixed-ligand complexes of ruthenium(III) containing tridentate chiral Schiff-base ligands $\left(\mathrm{H}_{2} \mathrm{TDL}^{*} \mathrm{~s}\right)$ derived from condensation of either d-glucose amine or 1-alanine with 3,5-di-tertiarybutylsalicyldehyde, and triphenylphosphine $\left(\mathrm{PPh}_{3}\right)$ or 2,2'bipyridine (bipy) had been studied. The ruthenium(III)complexes,

$\left[\mathrm{Ru}^{\mathrm{III}} \mathrm{Cl}\left(\mathrm{TDL}_{1}^{*}\right)\left(\mathrm{PPh}_{3}\right)_{2}\right]$

$\mathrm{H}_{2} \mathrm{TDL}_{1}^{*}=N$-3,5-di-(tertiaryburyl)salicylidine-D-glucosomine),

$\left[\mathrm{Ru}^{\mathrm{III}} \mathrm{Cl}\left(\mathrm{TDL}_{2}^{*}\right)\left(\mathrm{PPh}_{3}\right)_{2}\right]$

$\mathrm{H}_{2} \mathrm{TDL}_{2}^{*}=N-3,5$-di-(tertiaryburyl)salicylidine-L-alanine)

and $\left[\mathrm{Ru}^{\mathrm{III}} \mathrm{Cl}\left(\mathrm{TDL}_{2}^{*}\right)\right.$ (bipy) $\left.\mathrm{H}_{2} \mathrm{O}\right] \mathrm{Cl}$ (bipy $=2,2$ '-bipyridine) $]$ (3)

were characterized by analytical, spectral (UV and IR), molar conductivity, magnetic moment and electrochemical studies. Complex 1 exhibited remarkable enantioselcetivity toward epoxidation of unfunctionalized alkenes using tertbutylhydroperoxide (t-BuOOH) as terminal oxidant. Styrene, 4-chlorostyrene, 4-methylstyrene, 4-methoxystyrene, 1-methylcyclohexene and 1,2-dihydronaphthalene were effectively converted to their organic epoxides in the $70-95 \%$ at ambient temperature. A lesser enantioselectivity was observed when complexes 2 and 3 were used in the epoxidation of enlisted alkenes under identical experimental conditions. A mechanism involving intermediacy of a highvalent $\mathrm{Ru}(\mathrm{V})$-oxo species is proposed for the catalytic epoxidation process. The whole reaction mixture was stirred under illumination of visible light.

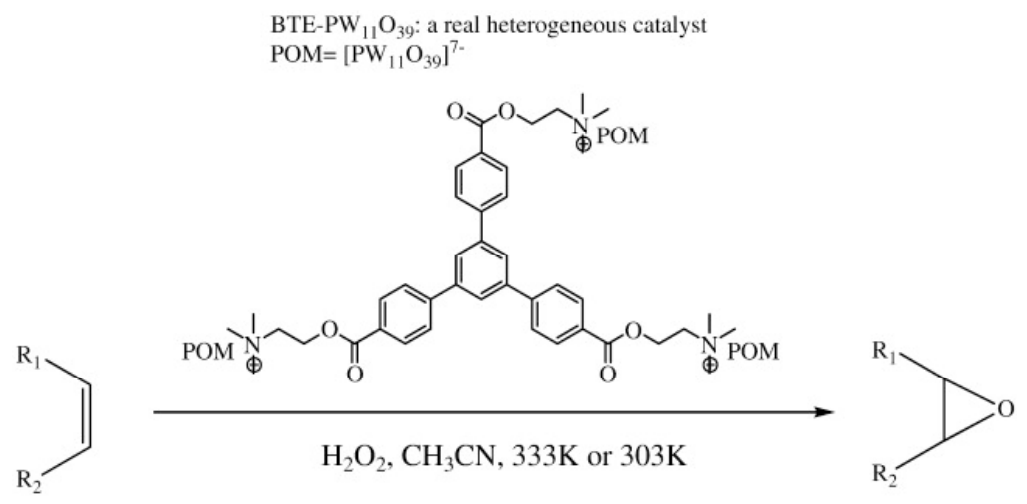


Mixed-ligand ruthenium catalyst including tridentate sugar-based chiral ligand and triphenylphosphines effect remarkably high asymmetric induction in epoxidation of styrenes using $\mathrm{t}-\mathrm{BuOOH}$ as a terminal oxidant. The formation is listed as follows:

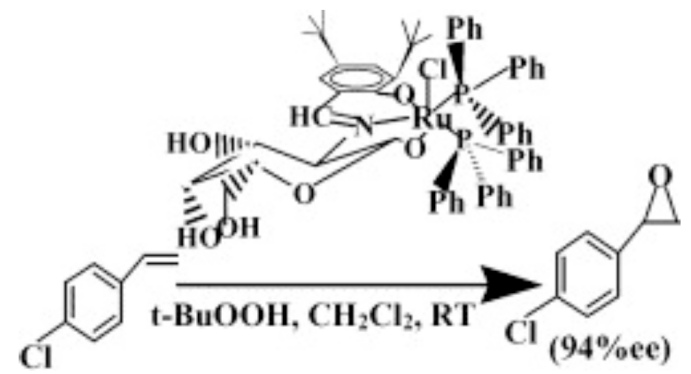

Visible Light Reaction of Olefins Under the Condition of 1 , 2-Diketone

J. A. S. J. Razenberg [10] introduced that oxidation of cyclohexene by (tetraphenylporphyrinato) manganese (III) acetate (Mn(TPP)OAc) and sodium hypochlorite as oxidant had been studied in a two-phase water-dichloromethane system in the presence of a phase transfer reagent. A kinetic study with this system reveals the following features: (1) the main product of the reaction (yield $\geq 80 \%$ ) is 1,2 -epoxycyclohexane; (2) in the presence of excess oxidant the reaction is zero order in cyclohexene; (3) the reaction order in $\mathrm{Mn}$ (III) concentration decreases from 1 to $\approx 0$ with increasing concentration of this catalyst; (4) the reaction order in hypochlorite decreases from 1 to 0 with increasing concentration of this reagent; (5) pyridine and substituted pyridines enhance the reaction rate. A Hammett treatment of the rate data for various substituted pyridines gives a $p$-value of $-1.00 ;$ (6) anchoring of $\mathrm{Mn}$ (TPP)OAc onto poly(vinylpyridine) or a polymer of an isocyanide, $(\mathrm{R}-\mathrm{N}=\mathrm{C}-2) n$, increases the reaction rate by a factor of 1.5 6.0 .

Based on these findings and on evidence from the literature, a mechanism for the epoxidation of cyclohexene was proposed. The key intermediate was an oxo-manganese (V) complex, which was formed from $\mathrm{Mn}$ (III) and hypochlorite in a pyridine-catalyzed step. The reaction mechanism is listed as follows:
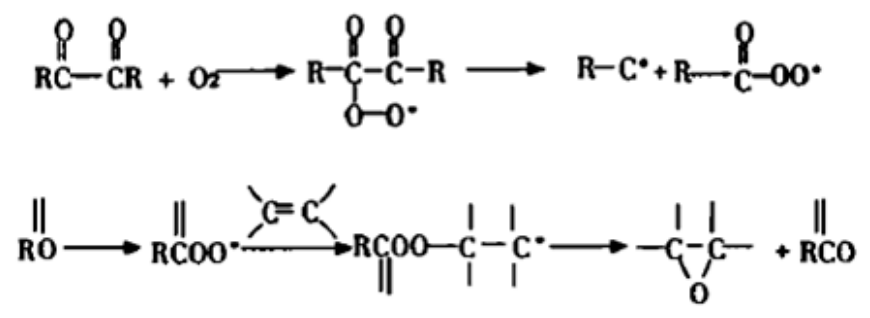

\section{CONCLUSION}

Catalytic oxidation of olefins is beneficial to the chemical process because it can provide more chemical production for the chemical plant. People have been studying on the reaction processing and can require some development. Catalytic oxidation of olefins are discussed that a deeply comprehending reaction mechanism of catalytic oxidation of olefins not only has very important significance, but also provides a theoretical foundation for the chemical plant. It is essential for people to understand catalytic oxidation of olefins in the modern chemical plant. And it can set up computer system to simulate the processing, and observe catalytic oxidation of olefins directly.

\section{REFERENCES}

[1] Liu, X.H.; You, H.J. Study on the development of olefin catalyzing and epoxidation reaction. Contem Chem Ind., 2004, 33(3), 146-149.

[2] Simandi, L.I. Catalytic activation of deoxygenates by metal. Kluwer Academic Publish 1992.

[3] Detlef, S.; Helmut, S. Catalytic gas-phase oxidation of olefins mediated by $\mathrm{Fe}\left(\mathrm{C}_{6} \mathrm{H}_{6}\right)^{+}$and a comparison of $\mathrm{Fe}(\mathrm{L})^{+}$complexes $(\mathrm{L}=$ benzene, pyridine, naphthalene). Eur. J. Org. Chem., 1995, (2), 429-431.

[4] Chimentão, R.J.; Barrab s, N.; Medina, F.; Fierro, J.L.; Sueiras, G.J.; Cesteros E.Y.; Salagre, P. Synthesis, characterization and catalytic activity of metal nanoparticles in the selective oxidation of olefins in the gas phase. J. Exp. Nanosci., 2006, 1(4), 399-418.

[5] Maria, Z. Catalytic liquid-phase oxidation in heterogeneous system as green chemistry goal-advantages and disadvantages of MCM41 used as catalyst. Catal. Today, 2004, 90(1-2), 145-150.

[6] Roger, A.; György, M.V.; Lo, G.; Arne, T.; Gillis, J. Enzymatic determination of glucose in a flow system by catalytic oxidation of the nicotinamide coenzyme at a modified electrode. Anal. Chim. Acta, 1985, 169, 237-247.

[7] Debabrata, C.; Sanghamitra, M.; Anannya, M. Epoxidation of olefins with sodium hypochloride catalysed by new Nickel (II)Schiff base complexes. J. Mol. Catal. A: Chem., 2000, 154(1-2), 58 .

[8] Zhang, Z.X.; Zhao, W.; Ma, B.C.; Ding, Y. The epoxidation of olefins catalyzed by a new heterogeneous polyoxometalate-based catalyst with hydrogen peroxide. Catal. Commun, 2010, 12(4), 318-322.

[9] Debabrata, C.; Susan, B.; Abdelkhalek, R.; Jacques, M. Highly efficient asymmetric epoxidation of alkenes with a novel chiral complex of ruthenium(III) containing a sugar based ligand and triphenylphosphines. J. Mol. Catal. A: Chem., 2006, 255(1-2), 283-289.

[10] Razenberg, J.A.S.J.; Van Der Made, A.W.; Smeets, J.W.H.; Nolte, R.J.M. Cyclohexene epoxidation by the mono-oxygenase model (tetraphenylporphyrinato) manganese (III) acetate-sodium hypochlorite. J. Mol. Catal,, 1985, 31(3), 271-287.

(C) Yongmei and Hongjun; Licensee Bentham Open.

This is an open access article licensed under the terms of the Creative Commons Attribution Non-Commercial License (http://creativecommons.org/licenses/by$\mathrm{nc} / 3.0 /$ ) which permits unrestricted, non-commercial use, distribution and reproduction in any medium, provided the work is properly cited. 